\title{
An application of Aluminum windows assembly line problem using FLB: An application of COMSOAL algorithm
}

\author{
Nima Pasha*
}

Department of Industrial Engineering, Tarbiat Modares University, Tehran, Iran

\begin{tabular}{l}
\hline C H R O N I C L E \\
\hline Article history: \\
Received July 18, 2014 \\
Accepted December 182014 \\
Available online \\
December 182014 \\
\hline Keywords: \\
Assembly Line Balancing \\
Workstation \\
Single Line Model \\
Computer Method of Sequencing \\
Operation for assembly lines \\
(COMSOAL) Algorithm \\
Simple Assembly Line Balancing \\
Problem (SALBP) \\
\end{tabular}
A B S T R A C T

\begin{abstract}
This paper presents an empirical investigation for line balancing in aluminum industry. Assembly line problems (ALB) are divided into three types, single-model assembly lines to handle (easy) problems to build a product that is designed to build one kind of product, multiple and mixed model to design for different kinds of products. This paper is an effort to describe comprehensively the solution to the problem for single-model assembly lines using some practical software package named FLB. The primary objective of aluminum assembly line balancing is optimal deployment activities subject to various limitations. The preliminary results of this paper indicate that the implementation of line balancing could reduce make span, significantly.
\end{abstract}

\section{Introduction}

Nowadays, assembly lines are flow-line production systems, which play essential role in the production systems (Boysen et al., 2006). Assembly lines are essential in the industrial productions of high quantity standardized commodities and they are more recently gained attention in low volume production of customized products. An assembly line is made up of a number of different workstations, arranged either in series or in parallel (Chica et al., 2012). Designing efficient assembly workshops may significantly increase profitability for many industries such as aluminum industry. Assembly line (AL) balancing systems are composed of stations performing a set of tasks. The assembly system has subsystems with some stations requirements (Rekiek et al., 2002). Assembly line balancing (ALB) and sequencing are active areas of optimization research in operations management. ALB came to the fact when the finished product is inclined to the perception of product modularity. The assembly line balancing problem is defined as the tasks are required assembling the final product to the stations. Initially, the permanent manufacturing conditions have been achieved, then production items flow along the line, and each workstation has an equal allotted time to finish their tasks (Fan et al., 2010).

\footnotetext{
* Corresponding author

E-mail address: nima_pasha@yahoo.com (N. Pasha)

(C) 2015 Growing Science Ltd. All rights reserved.

doi: $10.5267 /$ j.uscm.2014.12.004
} 
As the number of products increases because of the shift from mass production to mass customization, assembly line should be designed and worked to handle different challenging conditions (Hu et al., 2011). Sequence planning is very important problem in assembly line design. A large number of researches have been accomplished to find out the optimum sequences based on various criteria, such as process time, investment cost, and product quality (Zhu et al., 2012). Simple assembly line balancing problem (SALBP) is a simplified form of ALBP. Bryton (1954) is believed to be first to define SALBP and Salverson built the first mathematical model of SALBP and presented quantitative solving steps (Wei \& Chao, 2011). The number of workstations and complexity of design are not associated with the physical, material or procedural factors. There are some general design steps, which need to be taken into account such as problem formulation, breaking down the problem into sub-problem, grouping ideas, which must be investigated, redesigning assessment and implementation (Rekiek et al., 2002). Henry Ford is believed to be the first who invented the AL, which revolutionized the way cars have been made in terms of costs. He was the first to introduce a moving belt in the factory (Rekeik, 2006). Assembly line balancing can be described as the process of optimizing an assembly in terms of some certain factors such as cycle time, minimum number of workstation, which are calculated as follows,

Cycle Time is equal to "Normal Time (Services) + Allowanced Time" and the minimum number of

workstation is equal to $\frac{\sum S_{i}}{\text { Cycle Time }}$. Efficiency of production line has inverse relationship with Cycle Time (CT) as follows,

minimum number of workstation $=1-\frac{\sum \text { Alowance Time }}{\text { number of } \text { workstation } * \text { Cycle Time }}$

minimum number of workstation $=\frac{\sum s_{i}}{\text { number od workstation } * \text { Cycle Time }}$

Takt Time $(\mathrm{T} / \mathrm{T})$ is also equal to Takt Time $=\frac{T_{a}}{D}$ where $T / T$ is the work time between two consecutive units, $T_{a}$ is the net available time and $D$ represents demand. There are literally many software packages such "Computer Method of Sequencing Operation for assembly lines (COMSOAL)" for sequencing operations for assembly lines. COMSOAL is a method of balancing large complex machine-paced assembly lines as well as flexible line balancing (FLB).

\section{Modeling Aluminum Windows ALBP with COMSOAL Algorithm And FLB}

The classical single-model problem contains the following main characteristics:

- Mass-production of one homogeneous product;

- Given production process;

- Paced line with fixed cycle time c;

- Deterministic (and integral) operation times $\mathrm{t}_{\mathrm{j}}$;

- No assignment restrictions besides the precedence constraints;

- Serial line layout with m stations;

- All stations are equally equipped with respect to machines and workers;

- Maximize the line efficiency (Scholl \& Becker, 2006).

In this part, aluminum windows product line (See Fig. 1) is investigated and production processes, cycle times, process relationship, etc. are determined. These data are useful to solve SALBP with COMSOAL algorithm. Input entities are classified in three part profiles including accessories, glasses and raw materials, which are moved to product line. 


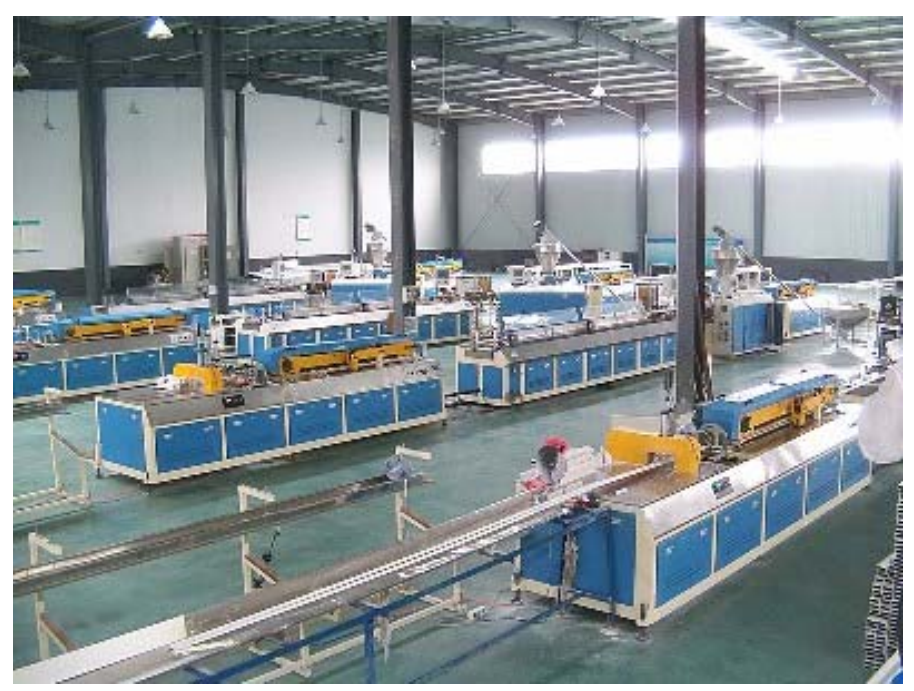

Fig. 1. Aluminium Windows Product Line

Production process chart of aluminium windows is shown in Fig. 2 as follows,

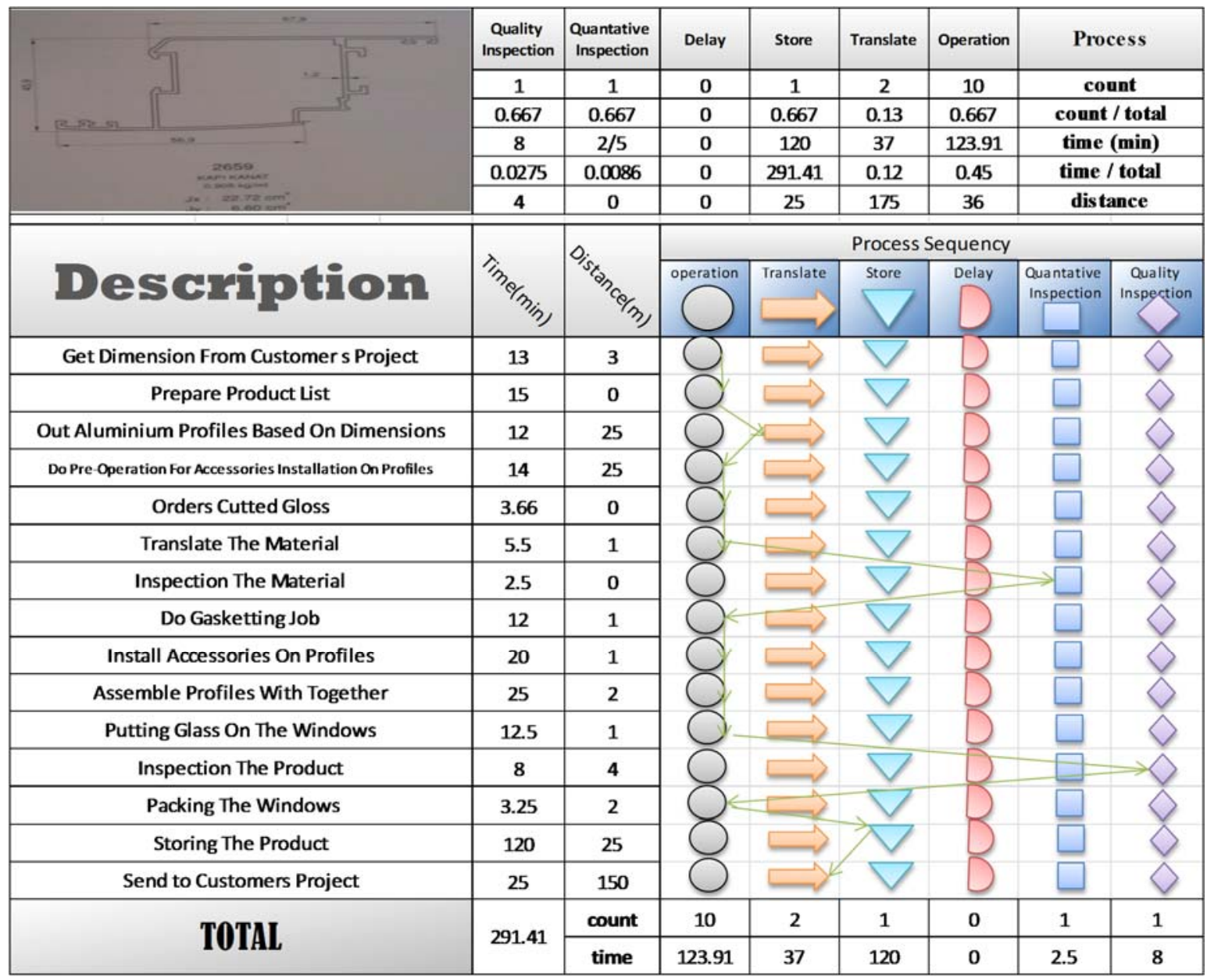

Fig. 2. Aluminium Windows production process chart

At this time, the relationships and sequences among operations are prepared and they are summarized in Fig. 3 as follows, 


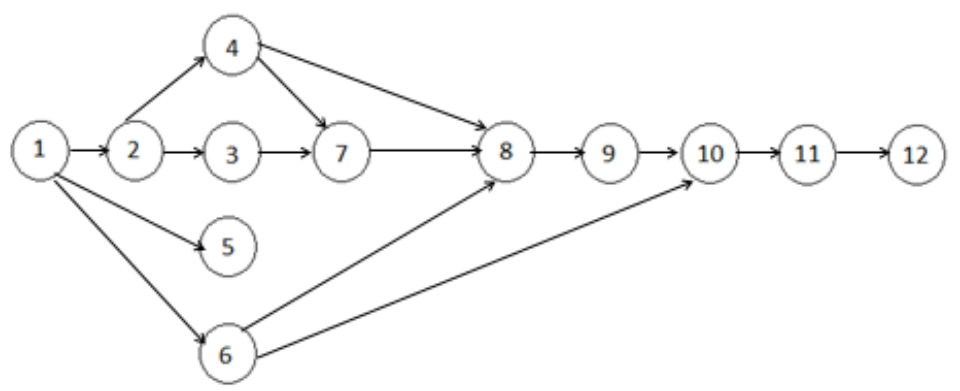

Fig. 3. Precedence diagram

The precedence diagram method demonstrates the scheduling activities for the proposed case study. In Fig. 3, boxes, referred to as nodes, are used to represent activities and connects them with arrows, which show the dependencies.

\section{Solving Aluminum Windows ALBP with COMSOAL Algorithm (By FLB)}

COMSOAL is a simple record-keeping technique, which allows a large number of possible sequences to be tested, quickly. In this method, only tasks that satisfy all the constraints are taken into account at each step. Besides, sequence saved if it is better than the previous upper bound and the bound is updated, accordingly. Efficiency depends on the data storage and processing structure. One of the differences between COMSOAL and other methods such as Ranked Positional Weight (RPW) algorithm is that COMSOAL, after solving the problem, devotes random operations to each workstation. FLB solves the problem based on COMSOAL Algorithm. Table 1 shows details of the data.

\section{Table 1}

T/T calculation with FLB

\begin{tabular}{|c|c|c|c|c|c|c|c|c|c|c|c|c|c|}
\hline No. & Takt Time & $\mathrm{N} / \mathrm{T}$ & $\mathrm{T} / \mathrm{T}-\mathrm{N} / \mathrm{T}$ & Efficiency & Workstations & Activities & No. & Takt Time & $\mathrm{N} / \mathrm{T}$ & $\mathrm{T} / \mathrm{T}-\mathrm{N} / \mathrm{T}$ & Efficiency & Workstations & Activities \\
\hline 1 & 24 & - & - & - & - & 12 & 30 & 53 & 45 & 8 & $95.40 \%$ & 4 & 12 \\
\hline 2 & 25 & 25 & 0 & $76.60 \%$ & 9 & 12 & 31 & 54 & 45 & 9 & $95.40 \%$ & 4 & 12 \\
\hline 3 & 26 & 26 & 0 & $82.90 \%$ & 8 & 12 & 32 & 55 & 45 & 10 & $95.40 \%$ & 4 & 12 \\
\hline 4 & 27 & 26 & 1 & $82.90 \%$ & 8 & 12 & 33 & 56 & 45 & 11 & $94.40 \%$ & 4 & 12 \\
\hline 5 & 28 & 28 & 0 & $88.00 \%$ & 7 & 12 & 34 & 57 & 45 & 12 & $94.40 \%$ & 4 & 12 \\
\hline 6 & 29 & 28 & 1 & $88.00 \%$ & 7 & 12 & 35 & 58 & 55 & 3 & $77.40 \%$ & 4 & 12 \\
\hline 7 & 30 & 29 & 1 & $84.90 \%$ & 7 & 12 & 36 & 59 & 55 & 4 & $77.40 \%$ & 4 & 12 \\
\hline 8 & 31 & 29 & 2 & $84.90 \%$ & 7 & 12 & 37 & 60 & 55 & 5 & $77.40 \%$ & 4 & 12 \\
\hline 9 & 32 & 29 & 3 & $84.90 \%$ & 7 & 12 & 38 & 61 & 55 & 6 & $77.40 \%$ & 4 & 12 \\
\hline 10 & 33 & 29 & 4 & $84.90 \%$ & 7 & 12 & 39 & 62 & 62 & 0 & $92.70 \%$ & 3 & 12 \\
\hline 11 & 34 & 29 & 5 & $84.90 \%$ & 7 & 12 & 40 & 63 & 62 & 1 & $92.70 \%$ & 3 & 12 \\
\hline 12 & 35 & 29 & 6 & $84.90 \%$ & 7 & 12 & 41 & 64 & 62 & 2 & $92.70 \%$ & 3 & 12 \\
\hline 13 & 36 & 29 & 7 & $84.90 \%$ & 7 & 12 & 42 & 65 & 62 & 3 & $92.70 \%$ & 3 & 12 \\
\hline 14 & 37 & 29 & 8 & $84.90 \%$ & 7 & 12 & 43 & 66 & 62 & 4 & $92.70 \%$ & 3 & 12 \\
\hline 15 & 38 & 38 & 0 & $90.70 \%$ & 5 & 12 & 44 & 67 & 62 & 5 & $92.70 \%$ & 3 & 12 \\
\hline 16 & 39 & 38 & 1 & $90.70 \%$ & 5 & 12 & 45 & 68 & 62 & 6 & $92.70 \%$ & 3 & 12 \\
\hline 17 & 40 & 38 & 2 & $90.70 \%$ & 5 & 12 & 46 & 69 & 62 & 7 & $92.70 \%$ & 3 & 12 \\
\hline 18 & 41 & 40 & 1 & $84.60 \%$ & 5 & 12 & 47 & 70 & 69 & 1 & $82.50 \%$ & 3 & 12 \\
\hline 19 & 42 & 40 & 2 & $84.60 \%$ & 5 & 12 & 48 & 71 & 69 & 2 & $82.50 \%$ & 3 & 12 \\
\hline 20 & 43 & 40 & 3 & $84.60 \%$ & 5 & 12 & 49 & 72 & 69 & 3 & $82.50 \%$ & 3 & 12 \\
\hline 21 & 44 & 42 & 2 & $82.10 \%$ & 5 & 12 & 50 & 73 & 69 & 4 & $82.50 \%$ & 3 & 12 \\
\hline 22 & $45 *$ & 45 & 0 & $95.40 \%$ & 4 & 12 & 51 & 74 & 69 & 5 & $82.50 \%$ & 3 & 12 \\
\hline 23 & 46 & 45 & 1 & $95.40 \%$ & 4 & 12 & 52 & 75 & 74 & 1 & $77 \%$ & 3 & 12 \\
\hline 24 & 47 & 45 & 2 & $95.40 \%$ & 4 & 12 & 53 & 76 & 74 & 2 & $77 \%$ & 3 & 12 \\
\hline 25 & 48 & 45 & 3 & $95.40 \%$ & 4 & 12 & 54 & 77 & 74 & 3 & $77 \%$ & 3 & 12 \\
\hline 26 & 49 & 45 & 4 & $95.40 \%$ & 4 & 12 & 55 & 78 & 74 & 4 & $77 \%$ & 3 & 12 \\
\hline 27 & 50 & 45 & 5 & $95.40 \%$ & 4 & 12 & 56 & 79 & 74 & 5 & $77 \%$ & 3 & 12 \\
\hline 28 & 51 & 45 & 6 & $95.40 \%$ & 4 & 12 & 57 & 80 & 74 & 6 & $77 \%$ & 3 & 12 \\
\hline 29 & 52 & 45 & 7 & $95.40 \%$ & 4 & 12 & & & & & & & \\
\hline
\end{tabular}

In this article, the aluminum windows assembly is solved with FLB. Takt Time (T/T) is the maximum time of operations in the workstations. Total time of operations in each workstation is N/T. This quantity is different for each workstation. Therefore, $T / T$ is equal or more than $N / T(T / T>=N / T)$. One of the factors to solve SALBP with COMSOAL is calculated by (T/T - N/T). In FLB, T/T can be 
determined by users, but they should try to find the optimum result between different T/T. For solving SALBP, assembly line efficiency, declining number of workstations, (T/T-N/T) and operations procedures should be considered. First, all of constrains should be entered in the software. Then, different quantities of $\mathrm{T} / \mathrm{T}$ should be entered so that the most productivity results for AL could be calculated. As we can observe from the results of Fig. 4, the efficiency of product line reaches a peak when T/T quantity is between 44 and 55 . This factor definitely depends on T/T. Besides, total cycle times of workstation (N/T) should be equal to T/T. Thus, forty fifth sample is the optimum result.

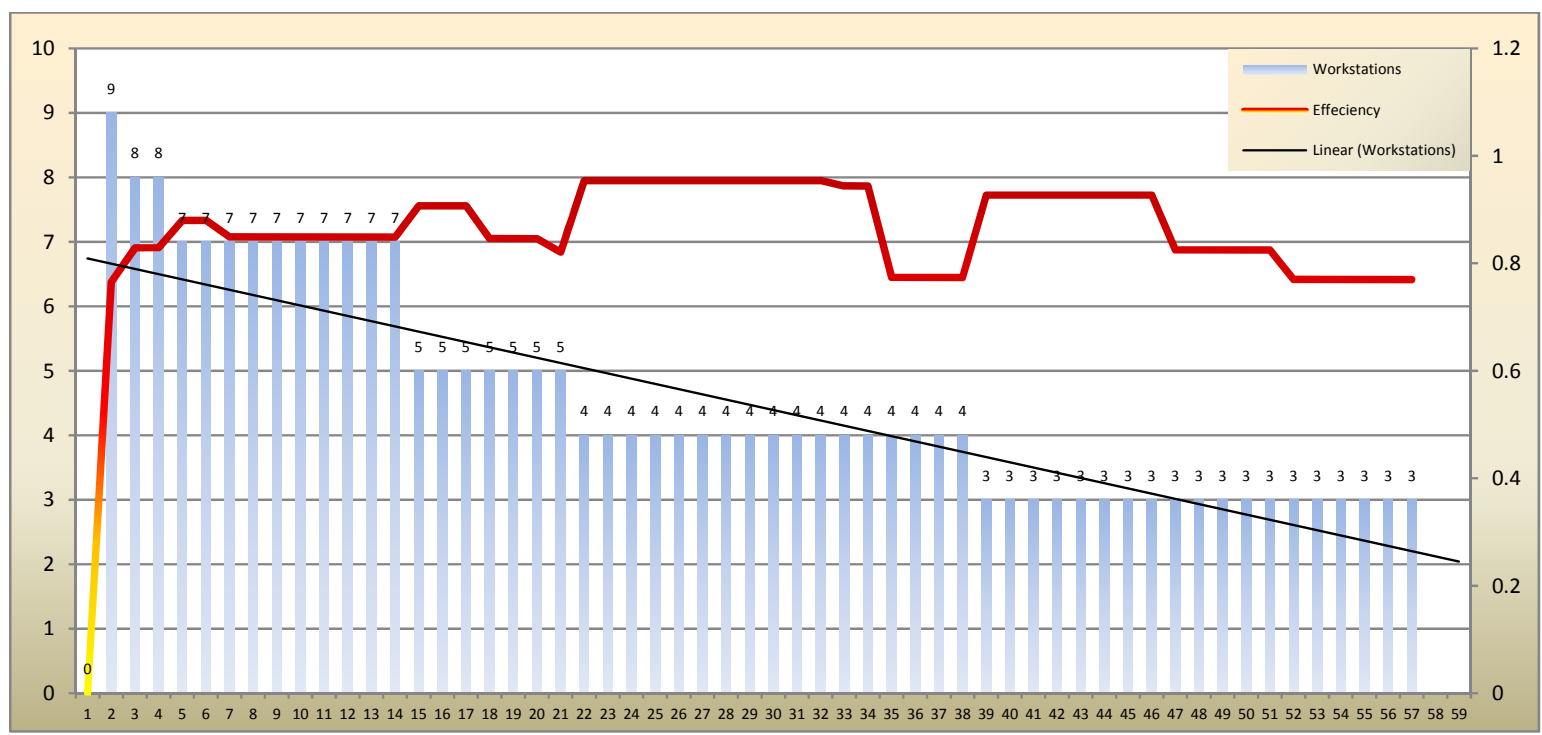

Fig. 4. Product line efficiency for $\mathrm{T} / \mathrm{T}$

In Fig. 4, the horizontal axis shows T/T quantities. Besides, the bar chart illustrates the number of workstations defined after solving for different samples and the line chart clarifies the efficiency of each sample. As the statistical evidence definitely indicates, as Tact Time increases, the number of workstation declines, slightly. The decreasing slop is approximately equal to -0.81 . Fig. 5 presents data on $\mathrm{T} / \mathrm{T}$ and workstation cycle times deviations. The deviation becomes zero periodically.



Fig. 5. T/T and N/T calculations for each samples 
Horizontal axis shows the $\mathrm{T} / \mathrm{T}$ and N/T quantities and vertical axis shows the sample results. In addition, Fig. 6 shows the deviation of Tack Time vividly.

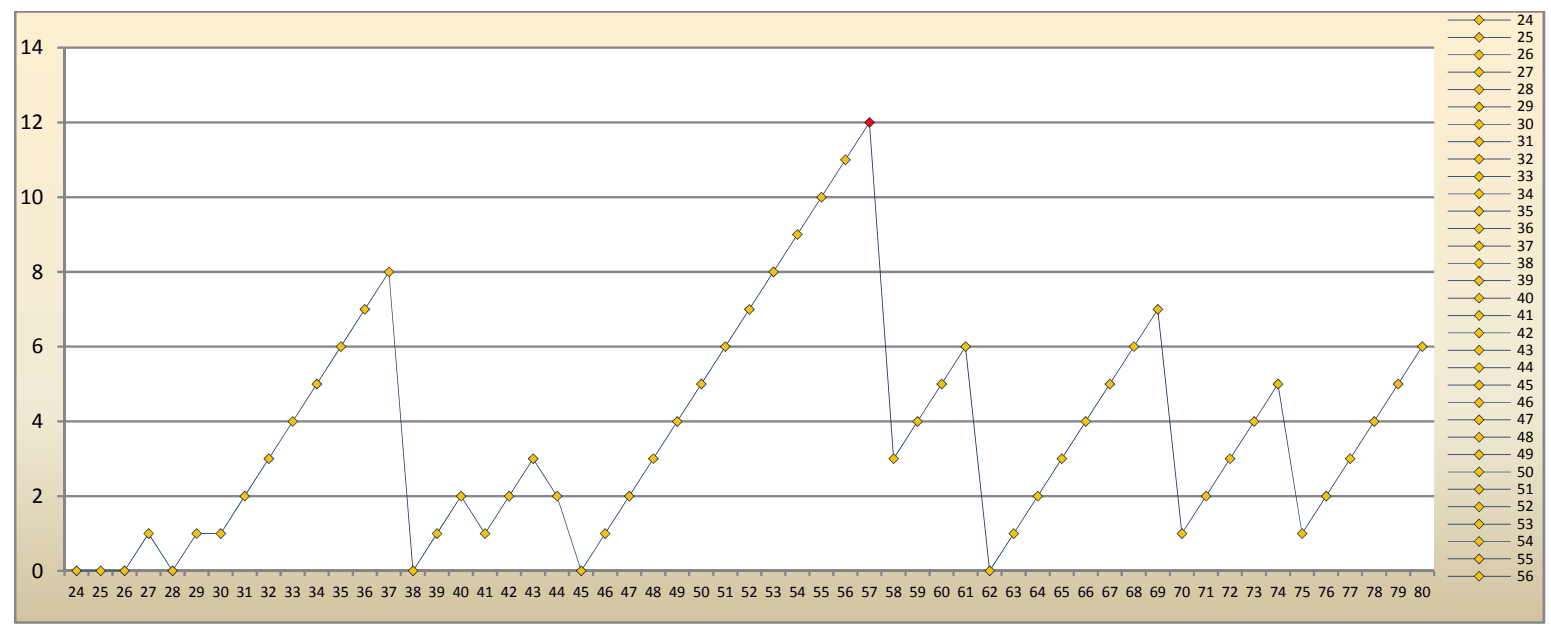

Fig. 6. Deviation between T/T and N/T

For 25, 26, 38, 45 and 62 quantities T/T - N/T becomes zero. So, the best quantity for T/T should be defined in order to operation allocation for each workstation be determined. Fig. 7 shows the information on FLB software results for this model.

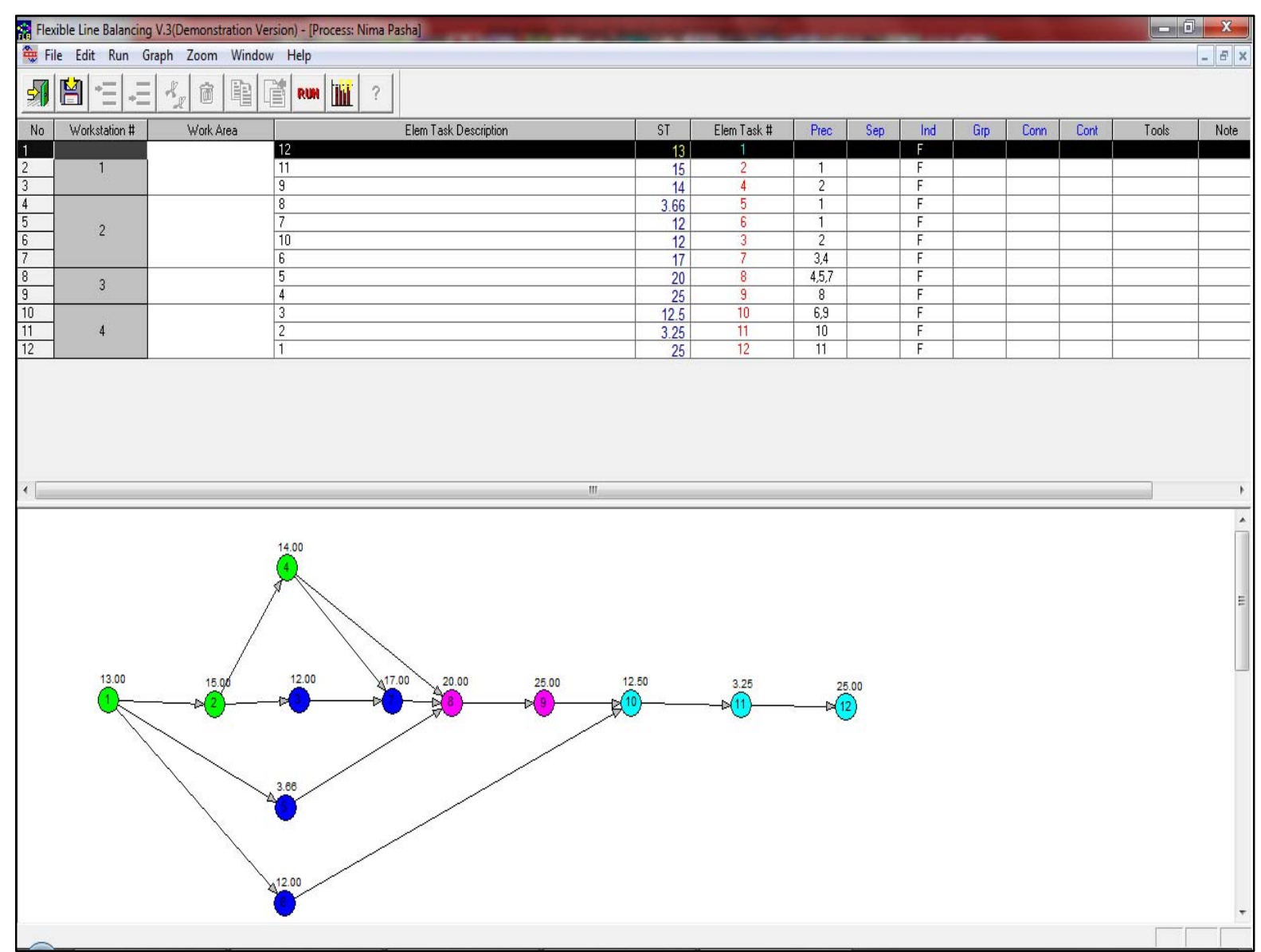

Fig. 7. Aluminium windows production process chart after solving SALBP with FLB 
Besides, as the figure shows, the first, $2^{\text {nd }}$ and the $4^{\text {th }}$ operations are devoted to the first workstation, $3^{\text {rd }}$ , $5^{\text {th }}, 6^{\text {th }}$ and $7^{\text {th }}$ operations are devoted to the second workstation, $8^{\text {th }}$ and $9^{\text {th }}$ operations are devoted to the $3^{\text {rd }}$ workstation and other operations are devoted to the $4^{\text {th }}$ workstation. These constrains include operation procedures relationship, human resources and equipment limitation, area restriction; contain operation, independence operation, etc. Fig. 8 shows the distribution of the operations associated with four mentioned workstations. One of the most important purposes of COMSOAL algorithm is to decrease the number of workstations.



Fig. 8. Operation and workstation

Fig. 9 shows the operations devoted to the workstations



Fig. 9. Operation and workstation

As the results show, in Table 1, different numbers of tack times are calculated for 53 samples. The best result for this factor depends on both product line efficiency and workstation operations CT. According to the results, the model with $\mathrm{T} / \mathrm{T}=45$ is chosen as the optimum result because this quantity has both factors specifications clarified. In this situation, deviation between $T / T$ and $N / T$ is 0 and the line balancing efficiency, which makes up 95.8\% provides desirable results. In addition, the number of workstations drops to four. These are the most important factors that have significant influence on the productivity. 


\section{Conclusion}

Assembly is a manufacturing process of consecutively assembling components in order to produce a final product. Assembly lines are designed to produce high-quality and low-cost standardized homogeneous products. This depends on demands, daily work time, equipment, parts assembly method, operation cycle times, etc. The purpose of assembly line is to decrease the idle time and workstation in order to use all the resources, more efficiency. This paper has presented an empirical investigation to use an efficient line balancing method for an application of aluminum window. The study has considered different activities associated with assembly problem and using COMSOAL algorithm for the implementation. The study can be extended for more real-world applications and new heuristics or meta-heuristics can be used to solve this type of problems more effectively.

\section{Acknowledgement}

The author would like to thank the anonymous referees for constructive comments on earlier version of this paper.

\section{References}

Bryton, B. (1954). Balancing of a Continuous Production Line, M.S. Thesis, Northwestern University, Evanston, IL.

Boysen, N., Fliedner, M., \& Scholl, A. (2007). A classification of assembly line balancing problems. European Journal of Operational Research, 183(2), 674-693.

Bukchin, Y., \& Rabinowitch, I. (2006). A branch-and-bound based solution approach for the mixedmodel assembly line-balancing problem for minimizing stations and task duplication costs. European Journal of Operational Research,174(1), 492-508.

Chica, M., Cordon, O., Damas, S., \& Bautista, J. (2012). Multiobjective memetic algorithms for time and space assembly line balancing. Engineering Applications of Artificial Intelligence, 25(2), 254273.

Fan, W., Gao, Z., Xu, W., \& Xiao, T. (2010). Balancing and simulating of assembly line with overlapped and stopped operation. Simulation Modelling Practice and Theory, 18(8), 1069-1079.

Hu, S. J., Ko, J., Weyand, L., ElMaraghy, H. A., Lien, T. K., Koren, Y., ... \& Shpitalni, M. (2011). Assembly system design and operations for product variety. CIRP Annals-Manufacturing Technology, 60(2), 715-733.

Rekiek, B., Dolgui, A., Delchambre, A., \& Bratcu, A. (2002). State of art of optimization methods for assembly line design. Annual Reviews in Control,26(2), 163-174.

Scholl, A., \& Becker, C. (2006). State-of-the-art exact and heuristic solution procedures for simple assembly line balancing. European Journal of Operational Research, 168(3), 666-693.

Wei, N. C., \& Chao, I. (2011). A solution procedure for type E simple assembly line balancing problem. Computers \& Industrial Engineering, 61(3), 824-830.

Zhu, X., Hu, S. J., Koren, Y., \& Huang, N. (2012). A complexity model for sequence planning in mixed-model assembly lines. Journal of Manufacturing Systems, 31(2), 121-130. 